\title{
Is unemployment and low income harmful to health? Evidence from Britain.
}

\author{
D. Cooper, W. D. McCausland, Ioannis Theodossiou \\ University of Aberdeen
}

November 17, 2014

\begin{abstract}
This study investigates how unemployment and income influence the length of time an individual remains in good health. This is a complex relationship since unemployment or low income deteriorates health but poor health can become a barrier to obtaining higher income or gaining re-employment. Data is from the British Household Panel Survey, using two measures of physical health: an index of mobility problems and a measure of self-assessed health. The results show that unemployment, low income and poor education adversely affect the time that people remain in good health. These results have important implications for public policy, particularly in an age of austerity when social protection mechanisms are under threat. In fact, the results suggest that to improve health and reduce health inequality more investment needs to be directed at policies that enhance labour force participation, improve education and reduce income inequality.

Keywords: unemployment, health

Acknowledgement 1 The financial support of the European Commission under the Fifth Framework Programme "Quality of Life and Management of Living Resources" (contract number: QLRT-2001-02292) is thankfully acknowledged. Helpful comments from Ian McAvinchey are gratefully acknowledged.
\end{abstract}




\section{INTRODUCTION}

"Evidence that health worsens in boom times indicates that economic progress need not have uniformly beneficial effects (... and ...) indicates that some previous advocates ... have overly enthusiastically cited an assumed pro-cyclical variation in health (when) arguing for macroeconomic stabilization policies."

Christopher J. Ruhm, 'Macroeconomic Conditions, Health and Government Policy' National Poverty Center conference address, July 2006.

The above view, originating from the work of (Ruhm, 2000), points to health improvements during periods of unemployment arising from reduced smoking and drinking, the increased opportunity to exercise and decreases in excessive working hours or dangerous working environments, despite medical evidence to the contrary. The intuitive appeal of a wide body of literature showing that individuals with low socioeconomic status, reflected in high unemployment experience or low income, are more disadvantaged in terms of health status compared to individuals who are "better-off" has been questioned in recent years. Yet there is medical and epidemiological evidence to show that unemployment, low income and poverty are detrimental to health, due to poorer financial resources, restricted access to health services, and adverse psychological effects.

This purpose of this paper is to shed some light on these competing claims by investigating how unemployment and income influence the length of time an individual remains in good health. This is a complex relationship since unemployment or low income deteriorates health but poor health can become a barrier to obtaining higher income or gaining re-employment.

There is a growing concern among policy makers that inequalities in health are widening (Wilkinson, 1986; Smith, 1999), across a wide spectrum countries from those where health service provision is largely public financed to those where there is a more modest public contribution. This is important for a number of reasons, not least because those languishing at the bottom of the health distribution are more likely to suffer poor health earlier, and have increased morbidity and mortality rates, than those at the top end of the distribution. In turn, this has implications in terms of reduced labour force participation, rendering the adverse effects of an ageing population more acute. Rose (1992) suggests that "the primary determinants of disease are mainly economic and social, and therefore its remedies must also be economic and social", and provides a constructive substitute to policies that merely seek to reduce health care provision to manage costs. Reducing the extent of socioeconomic inequality can be argued to improve the health and longevity of the most vulnerable in society and improve labour market participation and employment (Schuring et al., 2007). Indeed, Wilkinson and Pickett (2011) offered a range of evidence of a causal relationship on the detrimental effects of inequality on health and the social gradients of health. They also documented a number of case studies where policies aimed at decreasing income inequality led to significant improvements in population health.Moreover, in an age of austerity, there is increasing public concern on the effects of increased unemployment and reduced incomes on health - as one 
critic (Stewart, Times Higher Education Supplement) put it: 'Keynes pointed out in the long run we are all dead. Stuckler and Basu (2013) argue that, without government intervention, quite a lot more people are dead in the short run, too."

\section{EXISTING LITERATURE}

The relationship between health and socioeconomic status has received significant attention in the literature as reviewed in detail by Feinstein (1993) and Smith (1999). The detrimental effect of various indicators of low socioeconomic status (for example, early hardship, low income and poor education) on clinical health has been well documented in the epidemiological literature, particularly for women (Denton et al., 2004; Park et al., 2007; Thurston et al., 2005; Loucks et al., 2007; Khlat et al., 2009; Tseng and Petrie, 2014). From the point of view of public policy significance it is therefore essential to thoroughly investigate the mechanisms underpinning the relationship between socioeconomic status and health. Navarro (1990) showed that there are great disparities in health both in terms of mortality and morbidity, due to disparities in wealth and income, even if the effects of race are netted out. Furthermore, the unemployed who experienced the greatest financial hardship and shaming experiences reported the worst health outcomes, their lifestyles had deteriorated, their social life was reduced, their self-confidence had diminished and they enjoyed fewer leisure activities (Moser et al., 1986; Bartley, 1994; Björklund, 1985; Winkelmann and Winkelmann, 1998; Rantakeisu et al., 1999; Stern, 1983; Creed, 1998; Martikainen and Valkonen, 1996, 1998; Morris et al., 1994). Gaining employment substantially increases (mental) health (Huber et al., 2011) and "job insecurity" has negative effects on individual health status for both genders (Ferrie et al., 1995). Lundin et al. (2010), however, indicate that some part of the negative effect of unemployment on mortality may be attributable to over-representation among the unemployed of people with health statuses that enhance the risk of mortality. Goldsmith et al. (1996) find that spells of joblessness damages self esteem, and in particular, increases depression. Moreover, although Brenner (2005) details the negative effects of recession and unemployment on mortality, Catalano et al. (2011) in their survey of the health effects of economic decline, maintain that, while unemployment and low income negatively affect certain facets of health, such as depression, the outcomes on mortality are more mixed. However, Stuckler et al. (2011), looking at data in 10 European countries, finds that the suicide rate, which in large part drives short-term mortality rate fluctuations, increased in line with increases in unemployment following the financial crisis and recession of 2008. Wilkinson and Pickett (2011) argue that life expectancy, for example, within rich countries is not so much related to average income, but rather to income inequality. Other health and social problems, such as child wellbeing, mental illness, and obesity, are similarly more acute the more unequal the income distribution within a country. Moreover, they show that greater equality, though yielding greater benefits to the poor, also 
spread out to the rest of the population. They argue that, given the diminishing returns in wellbeing from economic growth, tackling the problems arising from inequality will be an important vehicle for improving health and wellbeing in the future. The length of the duration of unemployment acts negatively on health (Grobe and Schwartz, 2003). Goldsmith et al. (1997) show that the greater the duration of time out of the labour market, the lower the self-esteem of both men and women. Evidence suggests that variation in mortality rates and health is related more to individuals' socio-economic circumstances than to the level of medical provision (Mackenbach et al., 1990).

In contrast, other literature suggests that there are temporary reductions in mortality during sustained economic downturns (Ruhm, 2000, 2005, 2007; Gerdtham and Ruhm, 2006; Neumayer, 2004). Additionally, Schmitz (2011) fails to find any evidence in Germany of a negative effect of unemployment on satisfaction with health or mental health. Moreover, Salm (2009) shows that unemployment does not have detrimental effects on self-assessed health but rather individuals with poor health are being selected for the pool of the unemployed (Böckerman and Ilmakunnas, 2009) and there has been found no causal effect of exogenous job loss on various measures of physical and mental health. These claims are poorly supported by available medical evidence. Unemployment appears to be associated with psychological stress and the adoption of poor diets and unhealthy lifestyles (Stern, 1983; Morris et al., 1994; Hammarström, 1994). Moreover, Flint et al. (2013) shows that the transition into unemployment was associated with a negative effect on psychological well-being (and outweighs any positive effects of moving into employment). However, Bender et al. (2013) recently decompose the effect of unemployment on mortality into temporary and permanent effects. They show that, for most mortality indicators, though there is a temporary effect of an increase in unemployment which lowers mortality, there is also a permanent effect which increases mortality.

Overall, the complexity of the relationship between health and socioeconomic status arises because not only does unemployment or low income deteriorate health, but poor health status can become a barrier to obtaining higher income or gaining re-employment, thus can cause increased periods of being unemployed or out of the labour market. It implies that that the relationship between health and socioeconomic status is bi-directional. Individuals with higher socioeconomic status may enjoy better health because they have the income to invest in their health and afford better nutrition and better housing. They are also more likely to be better educated about the impact of health related behaviours like exercise, smoking and diet (Grossman, 1972). Yet, the socioeconomic status of an individual appears to be affected by their health, since poor health may adversely affect the individual's earning capacity. Thus there appears to be a downward spiral whereby declining socioeconomic status and deteriorating health negatively reinforce each other.

There is no doubt that the causal pathways in the socioeconomic status health relationship are complex in that socioeconomic status affects health and health affects socioeconomic status. This study attempts to circumvent this problem of endogeneity. It investigates how differences in labour market status 
and income influence the length of time a healthy individual remains in good health, after controlling for individual heterogeneity and a number of individual characteristics, by using accelerated failure time models. This methodology restricts the sample to those individuals in good health at the start of the observation period. The socioeconomic status of the individual is then recorded at the time deterioration of health status is declared. Thus, the probability of exit from a spell of good health, which is estimated over the whole time that the individual is healthy, cannot be thought of as having been caused by the socioeconomic status of the individual, recorded at the end of the time spell during which the individual is healthy. Thus the direction of causation is from socioeconomic status to health, and hence the problem of endogeneity is circumvented.

\section{METHODS}

\subsection{Data}

The data used in this study are from the British Household Panel Survey (BHPS). The BHPS is an annual survey consisting of a nationally representative sample of about 5,500 UK households recruited in 1991, containing a total of approximately 10,000 interviewed individuals. The sample is drawn from the Postcode Address File and all residents present at those addresses at the first wave of the survey were designated as panel members. These same individuals are re-interviewed each successive year and, if they split-off from original households to form new households, they are followed, and all adult members of these households are also interviewed. Similarly, new members joining sample households become eligible for interview. All members of the household aged 16 or over are interviewed. The core questionnaire covers a broad range of social science and policy interests including health, labour market behaviour, education, and income from employment. There is also a variable component containing questions which need to be asked less frequently than annually, new questions engendered by changing policy and research issues, and questions to elicit retrospective data on panel members' life histories before the first interview.

The sample used in this study uses 15 waves of the BHPS (1991-2005), yielding over 16,000 observations. Figure 1 gives the full description of the variables used together with their means.

\subsection{Measures of health}

Two measures of physical health outcomes are used (a) a mobility problems index, and (b) a self assessed health measure indicating how the individuals assessed their health compared to people of their own age.

(a) Mobility problems index. This health measure is a modified 'Activities of Daily Living' index (Katz et al., 1963). In the survey there are four questions asking respondents whether their health hinders them (i) doing their housework, 
(ii) climbing the stairs, (iii) getting dressed, and (iv) walking for more than ten minutes. The responses are coded in four levels, but since there are relatively few individuals in the BHPS who responded by reporting any limitations, this variable was collapsed into an indicator variable taking a value of one if there were any difficulties along any of these dimensions, and zero otherwise. Unfortunately, in waves 9 and 14, the set of questions on this issue was different from those used in the other waves. However, four questions are identified which corresponded to those in the earlier waves, and these are used for waves 9 and 14. Respectively these questions ask the respondents to reveal whether their health limits (i) moderate activities (moving a table, pushing a vacuum cleaner, bowls, and golf), (ii) climbing one flight of stairs, (iii) bathing or dressing, and (iv) walking half a mile. A dummy variable is introduced into the regressions to control for the possible effects of this change in definition.

(b) Self Assessed Health: This health measure is constructed from the individuals' responses to the question: "Please think back over the last 12 months about how your health has been. Compared to people of your own age, would you say that your health has on the whole been excellent, good, fair, poor, or very poor?" These categories are collapsed to a dummy variable where excellent and good states of health take the value one, and zero otherwise. An adjustment was again required for wave 9 . In wave 9 the SF36 questionnaire was introduced and therefore the question enquiring about an individual's general health was not exactly the same as in the earlier waves or wave 10 . In wave 9 , the question is, "in general would you say your health is excellent, very good, good, fair or poor?" That is, in wave 9 a "very good" category has been inserted between the "good" and "excellent" categories of other waves, and the "very poor" category has been deleted. Thus it is not possible to combine wave 9 with the other waves. To deal with this problem, a suitable adjustment was devised and an appropriate dummy variable introduced into the regressions to control for the possible effects of changes in definition.

The variable to be explained is the duration of a spell of good health for an individual. This variable is defined as follows. Individuals in good health are identified when they enter the survey, and tracked until their spell of good health ends. The spell of good health can end in one of three ways: (a) The individual may enter a spell of bad health; (b) leave the panel before the end of the panel whilst still in good health; or (c) still be in good health by the end of the panel. In the latter two cases, the period of good health is considered to be a censored observation. Then the length of the good health spell is measured (in years).

\subsection{Empirical Methodology}

The variable to be explained is the duration of a spell of good health for an individual (in years). Individuals who are observed as having good health at the beginning of the survey are recorded and are followed until the time that they report worsened health status, whereas an individual who does not report deterioration of health by the end of the survey is a censored observation. Cen- 
sored observations also include individuals who left the survey in good health but before the end of the survey and hence their current status is unknown.

The Accelerated Failure Time Model is used in this study. The socioeconomic status of the individual is recorded at the time he or she declares deterioration of health status while the probability of exit from a spell of good health is estimated over the whole time that the individual is healthy. Since the probability of exit from a spell of good health is estimated for a healthy individual and the labour market status or income is determined at the time of exit from a spell of good health, one should expect that lower health status cannot cause the labour market or income status. This methodology to restrict the sample to those individuals who exhibit good health at the initial point of the survey is often used in applied research in order to circumvent the endogeneity problem (Lynch et al., 1997; Buckley et al., 2004). This procedure allows the endogeneity problem to be circumvented.

The independent variables comprise employment status, and a number of individual characteristics (for example, occupation, level of education, marital status, level of income and other similar factors, as detailed in Table 1) recorded at the point at which the individual exits good health.

\subsection{Data analysis}

Accelerated Failure Time methodology is preferred over classical survival analysis, as it permits the estimation of duration dependence. A brief overview is presented in the appendix. The econometric analysis is conducted using Stata (using the "stset" and "streg" routines with a lognormal distribution of survival time, clustering by household identifier, and Accelerated Failure Time specified with correction for frailty). This methodology controls for a multiplicative effect of unobservable factors ("frailty") on the hazard function. This unobserved heterogeneity may occur because some observations have a greater propensity to fail, or are more "frail", than others. In addition, unobserved heterogeneity also controls for the circumstances of the individual before they enter the survey, or behaviours during the spell which are also unobserved. Thus, an individual who has enjoyed good health status over a long period may be engaging in certain lifestyle activities which affect the probability of improving or deteriorating his or her health status. Thus, for example, if the individual's lifestyle activities involve investments in health, such as taking exercise, healthy eating, and preventative medical care, then this will lessen the probability of worsening health - as the good health spell continues. In this case, there is negative duration dependence. Failure to account for effects of unobserved personal characteristics which decrease (increase) the probability of a good health spell ending may bias the results in favour of a negative (positive) duration dependence. In order to take into account the effects of unobserved heterogeneity, which may include not only personal family characteristics or unobserved lifestyle factors but also unobserved factors such as the duration of the good health spell prior to the entrance of the individual in the observation period or the state of affairs at the start of the spell (the so-called initial conditions), the hazard rate should 
be augmented by an additional random parameter to capture such random incidences of frailty. Additionally, it should be noted that any changes in health status within a twelve month period (for example and individual exiting and re-entering good health within the twelve month period) would not be captured by the annual observations of the survey.

\section{RESULTS}

First the results for the whole sample are examined. Figure 3 (a) plots the survival function for mobility problems by employment status, and Figure 3 (c) the survival function for self-assessed health by employment status. The unemployed (shown by a light grey line) have lower survival rates in good health than individuals in other employment statuses (shown by a dark grey line). The log-rank tests in Figure 6 confirm this.

The effects of socioeconomic factors of the duration of a spell of good health are shown in Figure 3. This paper shows that the key socioeconomic determinants of health duration are employment status, income and education. Firstly, unemployment has a detrimental effect on the duration of spells of good health. Unemployment decreases the duration of good health by around 19\%. Secondly, households with higher incomes enjoy longer spells of good health. Each $£ 10,000$ fall in income decreases the duration of good health by around $22 \%$ (30\% for self-assessed health). Finally, better educated individuals (for example, those with 'A' levels or degrees) have significantly longer spells of good health than those without the benefit of such a standard of education.

An important issue is "duration dependence" a term often used in studies of unemployment to refer to the probability of finding a job decreasing as the length of a spell of unemployment increases (Lancaster, 1979). Negative duration dependence in this context indicates how, as the length of the spell of good health increases, the probability of exiting good health decreases. This is reflected in the sign and significance of "log sigma" in Figure 3, which shows that, for the whole sample, while is no duration dependence for mobility problems, log sigma is significant and positive for self-assessed health, indicating negative duration dependence. The likelihood ratio test for heterogeneity, "log theta" confirms that there is no individual heterogeneity present.

Next, Figure 3 (b) plots the survival function for mobility problems by gender, and Figure 3 (d) plots the survival function for self-assessed health by

gender, which both highlight a clear difference between the survival rates of males (shown by the higher, light grey line) and females (shown by the lower, dark grey line). The higher male survival rate is confirmed by the log-rank test reported in Figure 7 (with males having a higher chance of remaining in good health than females).

The key socioeconomic determinants of health, namely, employment status, income and education, all have strong effects on health duration for both genders as shown in Figure 4. Importantly, the unemployed have shorter spells of good health than those in paid employment - a significant result for both genders 
(except for females using the self-assessed measure of health). Unemployment decreases the duration of good health by around $21 \%$ for males and $19 \%$ for females for the mobility problems measure of health. Household equivalised income has a significantly beneficial effect on the health of both genders. Each $£ 10,000$ fall in income decreases the duration of good health by around $19 \%$ for males and $22 \%$ for females using the mobility problems measure of health, whereas this gap widens to $36 \%$ (males) and $27 \%$ (females) for self assessed health. Those with a university degree or equivalent enjoy longer spells of good health. For the most part, the effect of A-levels on the duration of good health has a similar beneficial effect (except for men where the effect is not significant using the mobility problems measure).

For self-assessed health, there is negative duration dependence for both genders (log sigma is significant and positive). In other words, the longer the spell of good health, the lower the hazard of losing that good health status. Using the mobility problems measure of health, there is no duration dependence for males (log sigma is not significant), but positive duration dependence for females (log sigma is significant and negative).

Finally, the effect of socioeconomic status on health for different age groups is examined. This is an area of increasing concern in health policy given an ageing workforce. The results showing the socioeconomic effects on the duration of good health by age are presented in Figure 5. The sample is disaggregated into the 18-45 and the 46-65 age groups. The latter category represents include people who are working but approaching retirement, and whose health has important implications for labour force participation and retirement policies.

The present study shows that unemployment is found to have a generally negative effect on the duration of a good health spell, but in the case of mobility problems, only for the younger workforce. Unemployment decreases the duration of good health by around $19 \%$ for young workers using the mobility problems measure of health, for example. The effect of household equivalised income on health duration is similar for both age groups. Low income, it appears, has detrimental effects on health duration irrespective of age - each $£ 10,000$ fall in income decreases the duration of good health by up to $48 \%$ for older workers using the self assessed health measure for example. Thus, this study suggests that income is an important determinant of health duration which persists strongly throughout working life. As far as education is concerned, the key result being that education is shown as having a positive effect on health duration (but having A levels or a degree is not significant for older workers using the mobility problems health measure).

The hazard of losing good health is initially greater for the old than for the young, captured by the parameter "log sigma. Using the mobility problems measure of health, for the old, log sigma has a significant but very small negative value, whereas for the young, log sigma has a significant but very small positive value. This of course implies that sigma is smaller for the old than for the young, and hence the hazard function for the old lies above that for the young. For the self-assessed measure of health, log sigma is significant and positive for both age groups - indicating negative duration dependence. 


\section{DISCUSSION}

This paper investigates the effect of labour market status and income on the hazard of someone exhibiting deterioration in his or her health status. The literature suggests that the key socioeconomic determinants of health status are employment status, income and education, and the results of this paper show that these factors are also key determinants of health duration.

The key results show that unemployment, after controlling for income and education, appears to have a detrimental effect on the duration of good health, in line with Moser et al. (1986), Dahl (1993) and Bartley (1994) on the negative effects of unemployment on health; the findings of Rantakeisu et al. (1999) on the negative effect on health of various bad experiences associated with unemployment; Ferrie et al. (1995) on the adverse effect of the risk of unemployment on health; and Grobe and Schwartz (2003) on the negative effect of unemployment duration on health.

It is also shown that respondents with higher income have longer spells of good health. The positive effect of household equivalised income on health duration is in line with the literature on the effects of income or wealth on health (Ecob and Davey Smith, 1999; Lynch et al., 1997; Grundy and Holt, 2000; van Rossum et al., 2000; Wagstaf et al., 2001; Blakely et al., 2002; Gardner and Oswald, 2004; Goldman et al., 1995). The results are obtained after circumventing the problem of endogeneity in the duration of health - unemployment/income relationship since the individual is shown to have been in good health up to that point of becoming unemployed and only after that point does health deteriorate. Importantly, individual heterogeneity is important in determining the duration of a spell of good health and in particular this study shows negative duration dependence.

This study also shows that individuals who are better educated have significantly longer spells of good health, as in Muller (2002) and Sturm and Gresenz (2002), who identified education as being closely related to health and bettereducated individuals tend to adopt healthier lifestyles.

The results in this paper also reinforce those found in the existing literature looking at the relationship between socioeconomic status and health (Ecob and Davey Smith, 1999; van Rossum et al., 2000; Subramanian and Kwachi, 2004; Bezruchka et al., 2008) but additionally identify these factors also as the principal determinants of health duration, when gender differences are taken into account. In contrast to the conventional wisdom that females are more resilient to the effect of socioeconomic status on physical health (Ecob and Davey Smith, 1999), the results in this paper seem to support those of Theodossiou (1998), Everson et al. (2002), Griffin et al. (2002) and Flatau et al. (2000) which appear to reveal a greater vulnerability among females to the effect of socioeconomic status on psychological health.

Moreover, the literature suggests that health disparities arising from socioeconomic factors increase with age until after retirement (House et al., 1994; Van Ourti, 2003) and then weaken thereafter (Ecob and Davey Smith, 1999; O'Reilly, 2002; Theodossiou, 1998). The result that unemployment has a neg- 
ative effect on the duration of a good health spell, but in the case of mobility problems, only for the younger workforce, implies that labour force participation decisions are greatly affected by health deterioration and highlight the importance of policies aimed at reducing the negative effects of unemployment on health for the younger age group. The result that low income has detrimental effect on health duration irrespective of age suggests that income is an important determinant of health duration which persists strongly throughout working life. Education is shown to have a positive effect on health duration (but having A levels or a degree is not significant for older workers for the mobility problems health measure).

The findings in this paper also dovetail with recent work taking a comparative political economy perspective. McLeod et al. (2012a,b) use a varieties of capitalism approach to compare the relationship between unemployment and health across countries with different institutional frameworks of social protection. They find, for example, that the young, unemployed and poorly educated fare worse in terms of health in countries like the US, which have lower levels of social protection. This would indicate that the effect of the more liberal welfare state in the UK is to mitigate the effect of unemployment on health, and that reductions in social protection advanced during periods of austerity may result in worse health outcomes down the line. Bezruchka (2009) concurs that the evidence suggesting that the impact of economic cycles is less pronounced when there are greater social safety nets offers the opportunity to strengthen social support and decrease economic inequalities in order to yield health benefits for all. Möller et al. (2013) confirm the negative relationship between unemployment and health, but importantly consider spatial inequalities between the North and South of England. Worryingly, they find that the gap in unemployment between the least and most deprived has widened since the financial crisis of 2008. This in turn will widen health inequality between the most affluent and the most deprived regions. They advocate both the maintenance of social protection and the importance of measures to avoid unemployment. Bambra (2010) also identifies how changes in institutional factors may caution against comparison of the effects of unemployment in this century with those in previous recessionary periods. She highlights the deterioration in the welfare safety net, the increased stigmatisation of welfare benefits, the erosion of employment rights, and the falling away of social support mechanisms, and concludes that health consequences of unemployment now may be worse than in the past.

These results are important for their policy implications, since those at the foot of the health distribution are more likely to have lower life expectancy and experience poor health earlier in life, which in turn reduces labour force participation and exacerbates the adverse effects of an ageing population. Contrary to the view that unemployment is beneficial to health, as indicated in the opening to the paper, policies aimed at reducing health inequality improve health and longevity, increase labour market participation, and help offset the effect of an ageing population, offer a positive alternative to policies that seek only to reduce the costs of health care provision. 


\section{CONCLUSION}

This paper investigates the effects of unemployment and income on health in Britain and whether these effects vary between males and females and be- tween the older and younger workforce after controlling for lifestyle factors. It is found that individuals with low socioeconomic status are more disadvantaged in terms of health status compared to individuals who are "better-off'. Employment status, education and income have significant effects on the duration of spells of good health. Unemployment adversely affects the duration of spells of good health, and income exerts a significant positive effect. These findings are in stark contrast to those who argue that periods of unemployment are associated with positive health outcomes Ruhm (2000) and thus there is a diminished role for stabilisation policy. The findings in this paper do however dovetail with recent work taking a comparative political economy perspective. They support the thrust of the arguments of Wilkinson and Pickett (2011), who provided ample evidence that there is a causal relationship on the detrimental effects of inequality on psychosocial determinants of health and the social gradients of health. Furthermore, the findings of this paper chime with spirit of Stuckler and Basu (2013) that current austerity policies that decrease income and increase unemployment may lead to severe adverse effects on population health. The policy implications of the findings in this paper are therefore profound: reducing the extent of socioeconomic inequality and enhancing the likelihood of gainful employment are advantageous to the health and longevity of the most vulnerable in society, which further improves labour market participation, and they provide the basis for a constructive substitute to policies that merely seek to reduce health care provision to manage costs.

\section{References}

Bambra, C., "Yesterday once more? Unemployment and health in the 21st century," Journal of Epidemiology and Community Health 64 (2010), 213215 .

BARTLEy, M., "Unemployment and ill health: understanding the relationship.," Journal of Epidemiology and Community Health 48 (1994), 333-337.

Bender, K. A., A. Economou and I. Theodossiou, "The temporary and permanent effects of unemployment on mortality in Europe," International Labour Review 152 (2013), 275-286.

Bezruchka, S., "The effect of economic recession on population health," Canadian Medical Association Journal 181 (2009), 281-285.

Bezruchka, S., T. Namekata and M. Sistrom, "Improving economic equality and health: the case of post-war Japan," American Journal of Public Health 98 (2008), 216-221. 
BJörklund, A., "Unemployment and Mental Health: Some Evidence from Panel Data," The Journal of Human Resources 20 (1985), pp. 469-483.

Blakely, T., K. Lochner and I. KaWAchi, "Metropolitan area income inequality and self-rated health - A multi-level study," Social Science and Medicine 54 (2002), 65-77.

Brenner, H. M., "Commentary: Economic growth is the basis of mortality decline in the 20th Century - Experience of the United States 1900-2000," International Journal of Epidemiology 34 (2005), 1-8.

Buckley, N., F. Denton, A. Robb and B. Spencer, "The transition from good to poor health: an econometric study of the older population," Journal of Health Economics 23 (2004), 1013 - 1034.

Böckerman, P. And P. Ilmakunnas, "Unemployment and self-assessed health: evidence from panel data," Health Economics 18 (2009), 161-179.

Catalano, R., S. Goldman-Mellor, K. saxton, C. Margerison-Zilko, M. Subbaraman, K. LeWinn and E. Anderson, "The health effects of economic decline," Annual Review of Public Health 32 (2011), 431-450.

Creed, P. A., "Improving the mental and physical health of unemployed people: Why and how?," Medical Journal of Australia 168 (1998), 177-178.

DAHL, E., "Social inequality in health-The role of the healthy worker effect," Social Science and Medicine 36 (1993), 1077 - 1086.

Denton, M., S. Prus and V. Walters, "Gender differences in health: a Canadian study of the psychosocial, structural and behavioural determinants of health," Social Science and Medicine 58 (2004), 2585 - 2600.

Ecob, R. and G. Davey Smith, "Income and health: what is the nature of the relationship?," Social Science and Medicine 48 (1999), 693 - 705.

Everson, S., S. Maty, J. Lynch and G. Kaplan, "Epidemiologic evidence for the relation between socioeconomic status and depression, obesity, and diabetes," Journal of Psychosomatic Research 53 (2002), 891-895.

Feinstein, J., "The relationship between socioeconomic status and health: a review of the literature.," The Millbank Quarterly 71 (1993), 279Ü322.

Ferrie, J., M. Shipley, M. Marmot, S. Stansfeld and G. Smith, "Health effects of anticipation of job change and non-employment: longitudinal data from the Whitehall II study," British Medical Journal 311 (1995), $1264-1269$.

Flatau, P., J. Galea and R. Petridis, "Mental Health and Wellbeing and Unemployment," Australian Economic Review 33 (2000), 161-181. 
Flint, E., M. Bartley, N. Shelton and A. Sacker, "Do labour market status transitions predict changes in psychological well-being?," Journal of Epidemiology and Community Health 67 (2013), 796-802.

Gardner, J. AND A. OSWALD, "How is mortality affected by money, marriage and stress?," Journal of Health Economics 23 (2004), 1181-1207.

Gerdtham, U.-G. and C. Ruhm, "Deaths rise in good economic times: Evidence from the OECD," Economics and Human Biology 4 (2006), 298-316.

Goldman, N., S. Korenman and R. Weinstein, "Marital status and health among the elderly," Social Science and Medicine 40 (1995), 1717-1730.

Goldsmith, A. H., R. Vuem, Jonathan and W. J. Darity, "The impact of labor force history on self-esteem and its component parts, anxiety, alienation and depression," Journal of Economic Psychology 17 (1996), 183-220.

, "Unemployment, joblessness, psychological well-being and self-esteem: theory and evidence," Journal of Socio-Economics 26 (1997), 133-158.

Griffin, J., R. Fuhrer, S. Stansfeld and M. Marmot, "The importance of low control at work and home on depression and anxiety: do these effects vary by gender and social class?," Social Science and Medicine 54 (March 2002), 783-798.

Grobe, T. G. and F. W. Schwartz, "Unemployment and health status," Part of the Federal Health Reporting, Booklet 13, Robert Koch Institute (in German) (2003).

Grossman, M., "On the Concept of Health Capital and the Demand for Health," Journal of Political Economy 80 (March-Apr 1972), 223-55.

Grundy, E. And G. Holt, "Adult life experiences and health in early old age in Great Britain," Social Science and Medicine 51 (2000), 1061 - 1074.

Hammarström, A., "Health consequences of youth unemployment-review from a gender perspective," Social Science and Medicine 38 (1994), 699-709.

House, J., J. Lepkowski, A. Kinney, R. Mero, R. Kessser and A. HerZOG, "The social stratification of aging and health.," Journal of Health and Social Behavior 35 (1994), 213-234.

Huber, M., M. Lechner and C. Wunsch, "Does leaving welfare improve health? Evidence for Germany," Health Economics 20 (2011), 484-504.

Katz, S., A. Ford, R. Moskowitz, B. Jackson and M. Jaffe, "Studies of Illness in the Aged," JAMA: The Journal of the American Medical Association 185 (1963), 914-919. 
Khlat, M., F. Jusot and I. Ville, "Social origins, early hardship and obesity: A strong association in women, but not in men?," Social Science and Medicine 68 (2009), 1692 - 1699, part Special Issue: Early life effects on socioeconomic performance and mortality in later life: A full life course approach using contemporary and historical sources.

Lancaster, T., "Econometric Methods for the Duration of Unemployment," Econometrica 47 (1979), 939-956.

Loucks, E., D. Rehkopf, R. Thurston and I. Kawachi, "Socioeconomic Disparities in Metabolic Syndrome Differ by Gender: Evidence from NHANES III," Annals of Epidemiology 17 (2007), 19-26.

Lundin, A., I. Lundberg, L. Hallsten, J. Ottosson and T. HemmingsSON, "Unemployment and mortality - a longitudinal prospective study on selection and causation in 49321 Swedish middle-aged men," Journal of Epidemiology and Community Health 64 (2010), 22-28.

Lynch, J., G. Kaplan and S. Shema, "Cumulative Impact of Sustained Economic Hardship on Physical, Cognitive, Psychological, and Social Functioning," New England Journal of Medicine 337 (1997), 1889-1895.

Mackenbach, J., M. Bouvier-Colle and E. Jougla, "Avoidable mortality and health services: a review of aggregate data studies.," Journal of Epidemiology and Community Health 44 (1990), 106-111.

Martikainen, P. and T. Valkonen, "Excess mortality of unemployed men and women during a period of rapidly increasing unemployment," Lancet 348 (1996), 909-912.

- "The effects of differential increase of unemployment rates of occupation groups on changes in mortality," American Journal of Public Health 88 (1998), $1859-1861$.

Mcleod, C. B., P. A. Hall, A. Siddiqi and C. Hertzman, "How society shapes the health gradient: work-related health inequalities in a comparative perspective," Annual Review of Public Health 33 (2012a), 59-73.

McLeod, C. B., J. N. Lavis, Y. C. MacNab and C. Hertzman, "Unemployment and mortality: a comparative study of Germany and the United States," American Journal of Public Health 102 (2012b), 1542-1550.

Morris, J. K., D. Cook and A. Shaper, "Loss of employment and mortality," British Medical Journal 308 (1994), 1135-1139.

Moser, K., D. Jones, A. Fox and P. Goldblatt, "Unemployment and mortality: further evidence from the OPCS longitudinal study 1971-81," The Lancet 327 (1986), 365 - 367. 
Muller, A., "Education, income inequality, and mortality: a multiple regression analysis," British Medical Journal 324 (2002), 23.

Möller, H., F. Haigh, C. Harwood, T. Kinsella and D. Pope, "Rising unemployment and increasing spatial health inequalities in England: further extension of the North-South divide," Journal of Public Health 35 (2013), $313-321$.

Navarro, V., "Race or class versus race and class: mortality differentials in the United States," The Lancet 336 (1990), 1238 - 1240.

Neumayer, E., "Recessions lower (some) mortality rates: Evidence from Germany," Social Science and Medicine 58 (2004), 1037-1047.

O'ReILly, D., "Standard indicators of deprivation: do they disadvantage older people?," Age and Ageing 31 (2002), 197-202.

Park, M., K. Yun, G. Lee, H. Cho and H. Park, "A Cross-Sectional Study of Socioeconomic Status and the Metabolic Syndrome in Korean Adults," Annals of Epidemiology 17 (2007), 320-326.

Rantakeisu, U., B. Starrin and C. Hagquist, "Financial Hardship and Shame: A Tentative Model to Understand the Social and Health Effects of Unemployment," British Journal of Social Work 29 (1999), 877-901.

Rose, G., The Strategy of Preventive Medicine (Oxford: Oxford University Press, 1992).

Ruhm, C., "Are Recessions Good for Your Health?," The Quarterly Journal of Economics 115 (2000), 617-650.

Ruhm, C. J., "Healthy living in hard times," Journal of Health Economics 24 (2005), 341-363.

, "A healthy economy can break your heart?," Demography 44 (2007), 829-848.

SAlm, M., "Does job loss cause ill health?," Health Economics 18 (2009), 10751089.

Schmitz, H., "Why are the unemployed in worse health? The causal effect of unemployment on health," Labour Economics 18 (2011), 71-78.

Schuring, M., L. Burdorf, A. Kunst and J. Mackenbach, "The effects of ill health on entering and maintaining paid employment: evidence in European countries," Journal of Epidemiology and Community Health 61 (2007), 597-604.

Smith, J., "Healthy Bodies and Thick Wallets: The Dual Relation between Health and Economic Status," Journal of Economic Perspectives 13 (Spring 1999), 145-166. 
Stern, J., "The relationship between unemployment, morbidity and mortality in Britain," Population Studies 37 (1983), 61-74.

Stuckler, D. And S. Basu, The Body Economic: Why Austerity Kills (London: Allen Lane, 2013).

Stuckler, D., S. Basu, M. Suhrcke, A. Coutts and M. McKee, "Effects of the 2008 recession on health: a first look at European data," The Lancet 378 (2011), 124-125.

Sturm, R. and C. Gresenz, "Relations of income inequality and family income to chronic medical conditions and mental health disorders: national survey," British Medical Journal 324 (2002), 20.

Subramanian, V. And I. Kwachi, "Income inequality and health: what we have learned so far?," Epidemiologic Review 26 (2004), 78-91.

Theodossiou, I., "The effects of low-pay and unemployment on psychological well-being: A logistic regression approach," Journal of Health Economics 17 (January 1998), 85-104.

Thurston, R., L. Kubzansky, I. Kawachi and L. Berkman, "Is the Association between Socioeconomic Position and Coronary Heart Disease Stronger in Women than in Men?," American Journal of Epidemiology 162 (2005), 5765 .

Tseng, F.-M. And D. Petrie, "The Implications for Health, Depression, and Life Satisfaction from a Permanent Increase in Income for the Disadvantaged Elderly: Evidence from Taiwan," Review of Social Economy 72 (2014), 311 Ü336.

VAn Ourti, T., "Socio-economic inequality in ill-health amongst the elderly: Should one use current or permanent income?," Journal of Health Economics 22 (March 2003), 219-241.

van Rossum, C., H. Van De Mheen, J. Mackenbach and D. Grobbee, "Socioeconomic status and mortality in Dutch elderly people," The European Journal of Public Health 10 (2000), 255-261.

Wagstaf, A., P. PaCi And H. Joshi, "Causes of inequality in health : who are you? where do you live? or who your parents were?," Policy Research Working Paper Series 2713, The World Bank, November 2001.

Wilkinson, R., Class and Health: Research and Longitudinal Data, chapter Income and Mortality (London, Tavistock, 1986).

Wilkinson, R. And K. Pickett, The Spirit Level: Why Greater Equality Makes Societies Stronger (Penguin Books, 2011).

Winkelmann, L. And R. Winkelmann, "Why Are the Unemployed So Unhappy? Evidence from Panel Data," Economica 65 (February 1998), 1-15. 


\section{Appendix: The Accelerated Failure Time Model}

The natural logarithm of the survival time (namely, the duration of a spell of good health) is expressed as a linear function of the covariates:

$\ln t_{j}=x_{j} \beta+\sigma z_{j}$

$t_{j}=\exp (X \beta) t_{0}^{\sigma} ; t_{0}=\exp (z)$

where $x_{j}$ is a vector of covariates, $\beta$ is a vector of regression coefficients, $\sigma$ is a scale parameter, and $z_{j}$ is the error. Depending on the assumed density for $z_{j}$ the following models can be derived: for normal density, the lognormal model; for logistic density, the log-logistic model; and for extreme value density, the exponential and Weibull models. The term $\alpha$ represents a multiplicative effect of frailty on the hazard function, which is discussed in detail below.

Since there are a number of possible distributions that could be encompassed within the above, the Akaike Information Criterion (AIC) can be used in order to identify the density which best describes the data at hand. The AIC is based on the log likelihood function and takes into account the number of parameters that have to be estimated. It is defined as:

$A I C=-2(\log$ likelihood $)+2(c+p+1)$

where $c$ is the number of variables in the model, and $p$ is the number of model-specific ancillary parameters. The best density is the one with the lowest AIC (see Kalbfleisch and Prentice (2002) and Lancaster (1979).

Four distributions are considered: exponential, Weibull, lognormal and loglogistic. The AIC criterion was used to discriminate between them and indicated the lognormal distribution is the most appropriate for all disaggregations. In an AFT model a positive coefficient indicates that a unit increase in the relevant covariate delays failure (namely, the end of a spell of good health) and therefore increases the length of the spell of good health.

The survival times are affected by unobservable factors. The effect of these unobserved factors on the hazard rate is known as unobservable heterogeneity or frailty. Unobserved heterogeneity may occur because some observations have a greater propensity to fail, or are more "frail", than others. In addition, unobserved heterogeneity also includes the circumstances of the individual before they enter the survey, or behaviours during the spell which are also unobserved. Thus, an individual who has enjoyed good health status over a long period may be engaging in certain lifestyle activities which affect the probability of improving or deteriorating his or her health status. Thus, for example, if the individual's lifestyle activities involve investments in health, such as taking exercise, healthy eating, and preventative medical care, then this will lessen the probability of worsening health - as the good health spell continues, there is negative duration dependence. In addition, failure to account for effects of unobserved personal characteristics which decrease (increase) the probability of a good health spell ending may bias the results in favour of a negative (positive) duration dependence (Heckman and Borjas (1990), Lancaster, 1979). In order to take into account the effects of unobserved heterogeneity (this may include not only personal family characteristics or unobserved lifestyle factors but also unobserved factors such as the duration of the good health spell prior to the 
entrance of the individual in the observation period or the state of affairs at the start of the spell - the initial conditions), the hazard rate should be augmented by an additional random parameter to capture such random incidences of frailty. This is achieved by introducing frailty as a multiplicative effect, $\alpha$, on the hazard function:

$h(t, \alpha)=\alpha h(t)$

where $h(t)$ is the hazard function without frailty. The corresponding survival function will therefore be

$S(t, \alpha)=(S(t))^{\alpha}$

It can be shown that the population survival function will be

$$
S_{\theta}(t)=\int_{0}^{\infty}(S(t))^{\alpha} g(\alpha) d \alpha
$$

where $g(\alpha)$ is the probability density function of $\alpha$. It is standard to assume that the frailty, $\alpha$, is a random positive quantity with unit mean and variance $\theta$. The frailty distribution can be any continuous distribution of positive numbers with expectation one and finite variance, $\theta$. In this paper it is assumed that frailty has a Gamma distribution with parameters $\left(\frac{1}{\theta}, \theta\right)$. It can be shown that in this case the survival function will be

$$
S_{\theta}(t)=(1-\theta \ln (S(t)))^{-\frac{1}{\theta}}
$$

where $S_{\theta}(t)$ is the proportion of the population surviving past time $t$ (the survival function for the population) and $S(t)$ is the probability of an individual surviving past time $t$ (the survival function that corresponds to the non-frailty hazard $h(t))$.

\subsection{References for Appendix}

Heckman, J. and Borjas, G. (1990), "Does Unemployment cause future Unemployment? definitions, Questions and Answers from a Continuous Time Model of Heterogeneity and State Dependence", Economica, 47: 247-283.

Kalbfleisch, J.D. and Prentice, R.L. (2002) "The statistical analysis of failure time data", 2nd ed. New York, John Wiley and Sons.

Lancaster, T. (1979) "Econometric methods for the duration of unemployment" Econometrica 47(4): 939-956.

\section{Figures}




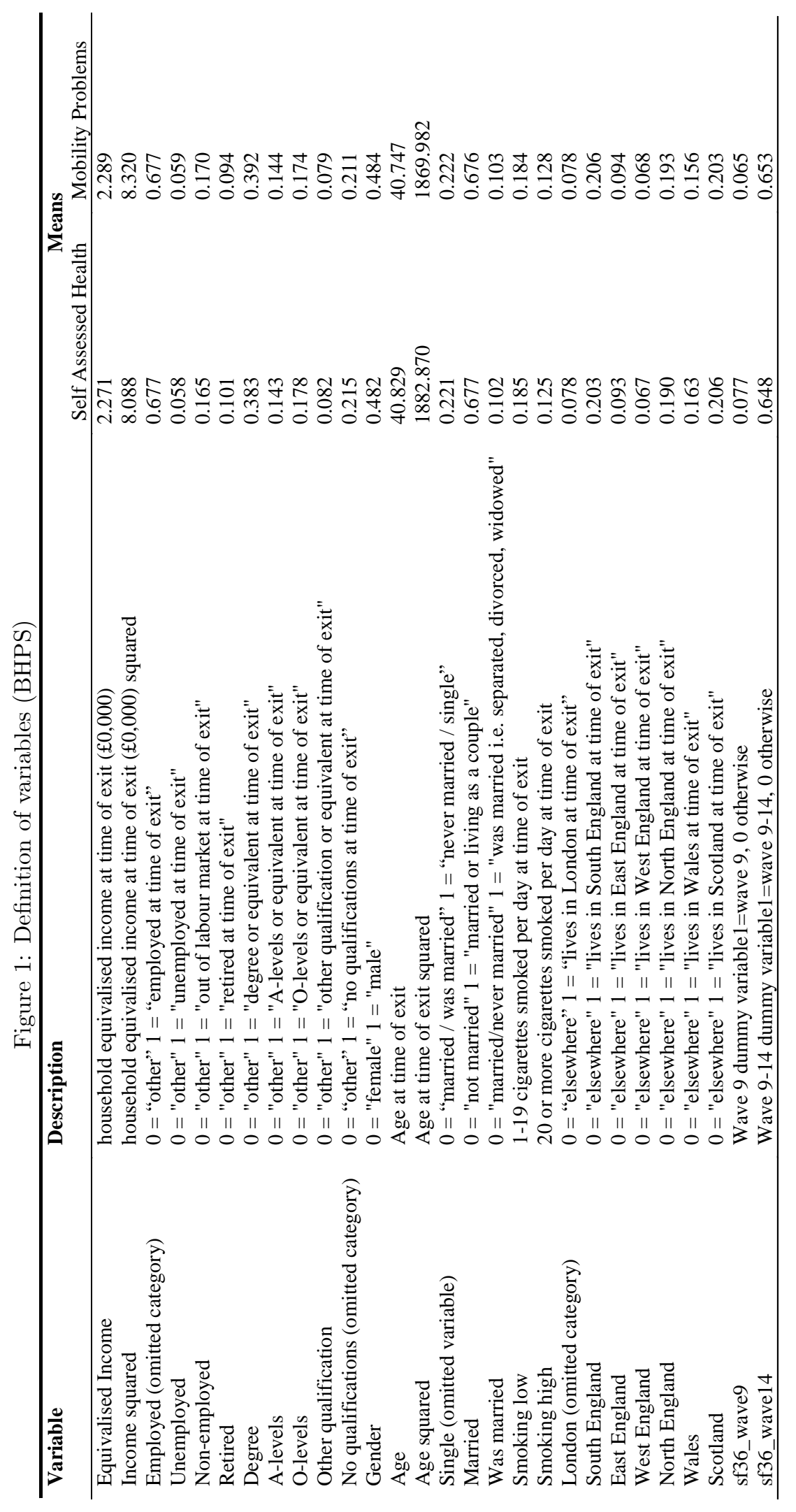




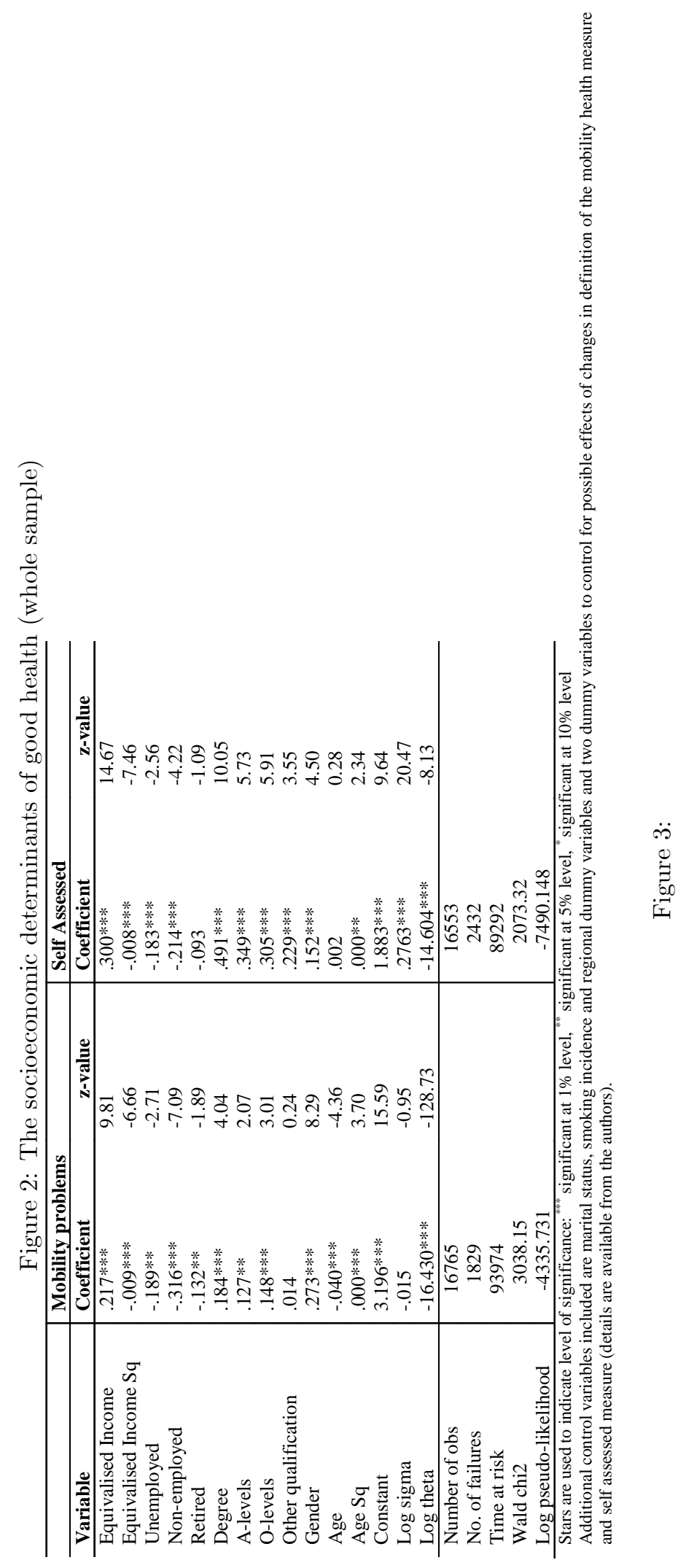




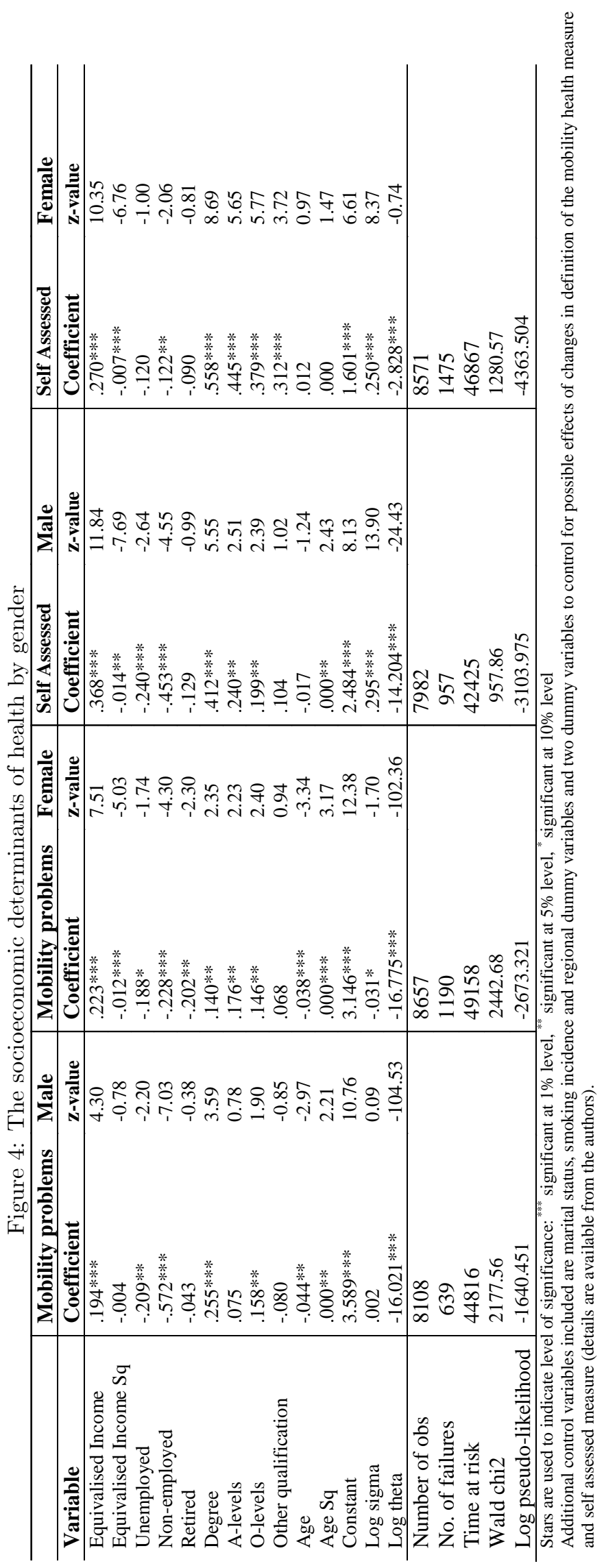




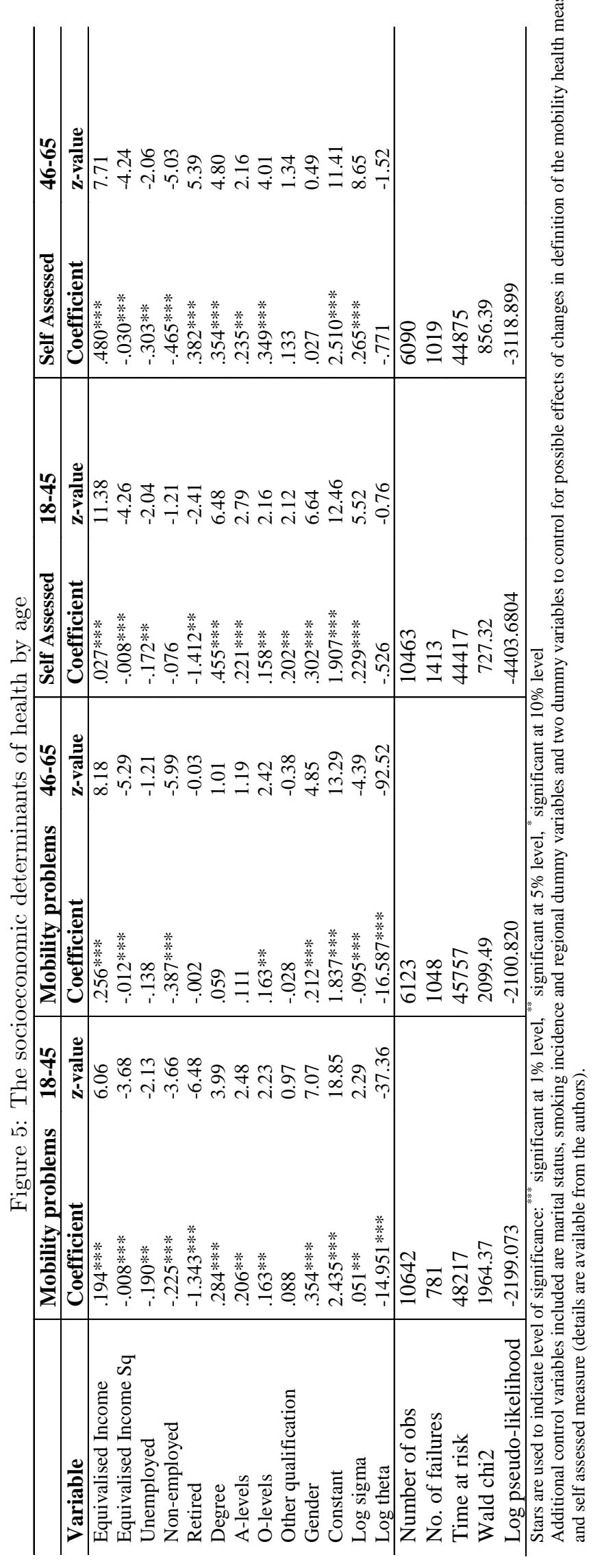



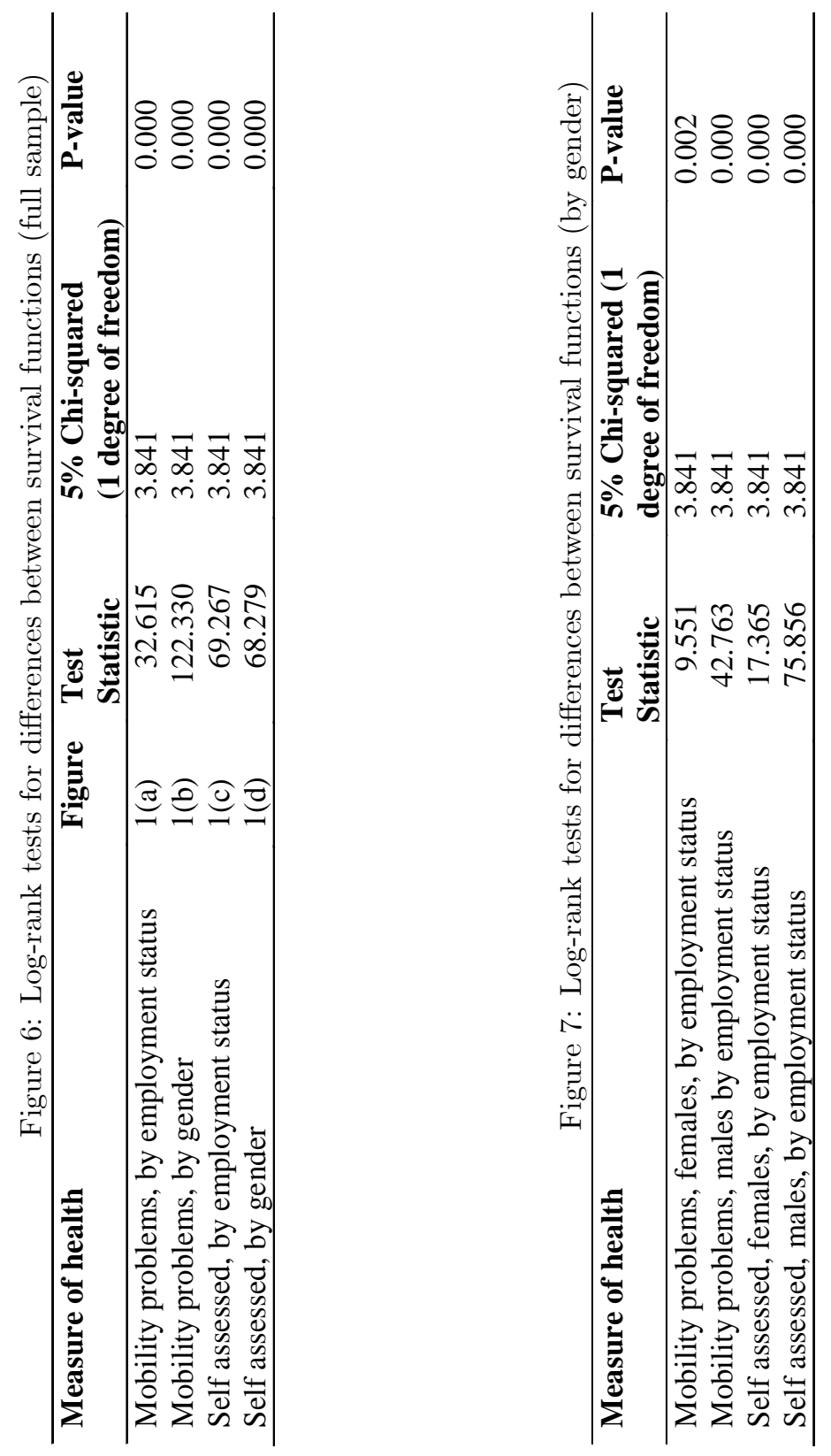